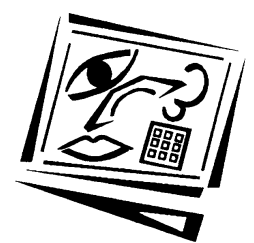

\title{
Learners' reflections on and perceptions of computer- mediated communication in a language classroom: A Vietnamese perspective
}

\author{
Long V. Nguyen
}

University of Danang

\begin{abstract}
The paper examines Vietnamese learners' reflections on and perceptions of the application of computer-mediated communication (CMC) into collaborative learning. Data for analysis included an evaluation questionnaire, consisting of 24 4-point Likert scale items, appended with six open-ended questions, and transcripts of 15 , out of 30, teacher trainees from a TEFL (Teaching English as a Foreign Language) class who volunteered to participate in informal interviews. Several inferences were drawn from the results. The majority of participants enjoyed the technology-enhanced class in general. There were approximately equal numbers of students who preferred synchronous $\mathrm{CMC}$, asynchronous $\mathrm{CMC}$, or a combination of both. The students reported that the course helped improve their computer skills and collaborative experience, while they remained sceptical about improvements to their English language skills. More involvement in learning was observed during and after the course. In addition, the participants expressed confidence that they would attend similar courses in future and were willing to recommend this technology-embedded course to the next generations of students.
\end{abstract}

\section{Introduction}

There have been two widely known trends in classroom research and practice in terms of pedagogical reformation. First, a social turn in language education (Block, 2003; Lantolf \& Thorne, 2007) has urged educators and teachers to seek more comprehensive methods and approaches to classroom practices. Attention has transferred from psycholinguistic approaches to sociocultural perspectives, emphasising language development through meaningful social interactions (Norton, 2009). As a result, a pedagogical shift has naturally moved from a narrow focus on individual learning to more contextual and sociocultural approaches to language development (Stahl, Koschmann \& Suthers, 2006). Collaborative learning (McLoughlin, 2002), therefore, seems to have got on the stage and has been gaining popularity in the field of language education.

Together with the social turn, the application of computer-mediated communication (CMC) to teaching and learning (Nguyen, 2008; Thorne, 2008), as the second trend, has experienced a remarkable increase over the past two decades, partly due to the rapid evolution of information and communication technology (ICT) and mainly because "more and more language instructors are integrating the use of technology into their classroom" (Chun, 2008, p. 16). CMC has introduced us, language teachers and researchers, to the idea of new literacies; and at the same time has blurred the line 
between written and oral communication (Kern, 2006) by "combining the interactivity of speech with the permanence of writing" (Fang \& Warschauer, 2004, p. 304). Researchers are constantly exploring how CMC, both synchronous and asynchronous, may help or hinder the learning process in particular sociocultural settings. These two trends have married collaborative learning and CMC so as to set up a fashionable style of learning, namely computer-mediated collaborative learning, or CMCL. In other words, collaborative learning and CMC have developed in parallel in a mutually supportive way. To date, collaborative learning through technology mediation and developing computer literacy through social/academic interaction is the trend in higher education programs (Warschauer, 2010).

Unlike intercultural CMCL (Nguyen, 2010; O'Dowd, 2007), which describes learning situations in which participants are from different linguistic and/or cultural communities, intracultural CMCL engages learners sharing the same language and/or culture and is popularly referred to as classroom-based CMC. A short period of twenty years has experienced an exponentially increased number of studies in this subfield of language education (see Abrams, 2006 for an extensive review). A study by Liu and Sadler (2003), for instance, examined the effect and affect of in-class peer exchanges in electronic versus traditional modes defined as face to face. Though data analysis revealed that face to face interaction was more effective than MOO communication (MOO stands for MUD, Object-Oriented, and MUD stands for Multi-User Domain), the participants tended to find the online discussion more appealing and pleasant.

Conversely, these learners expressed their negative attitudes towards 'timeconsuming' word editing and in favour of paper-based peer review. Another study by Lee (2010), related to examining learners' perceptions of online collaboration, showed that technology-enhanced learning had a constructive impact on the development of students' writing skills through collaborative engagement. Learners in the study expressed their satisfaction with the open-ended task types on wikis that empowered them to be creative and at the same time focus on form. In general, it is suggested from these studies that technology fosters learners' attitudes to learning and creates a positive collaborative learning environment; and, more importantly, that CMCL does not automatically ensure the successfulness of the integration of CMC into language education. Rather, an extensive investigation of learners' reflections on and awareness of the application of various CMC tools in collaborative learning is needed.

\section{ICT application at the College of Foreign Languages}

Though there are not as yet any specific indications of applying ICT in language education in the research literature, Vietnam has recently conducted several national and international conferences related to strengthening the application of ICT in education and administration management as part of Decree 64 (Vietnamese Government, 2008). Productively, the academic year 2008-2009 was themed by the Ministry of Education and Training as "The Year of ICT Application", connecting schools to the Internet and integrating new technologies into the curriculum. This promotion, which aims to improve teaching quality and renovate educational management, is considered as one of the initial steps in introducing and naturalising technology into the Vietnamese educational system.

As in many other universities and colleges, the use of computer technology is still quite limited at the College of Foreign Languages (CFL), University of Danang, both at 
the managerial level and in teaching and learning, in spite of having been promulgated and encouraged from the governmental level (Vietnamese Government, 2008). While there is a website for the college, it is in Vietnamese, in spite of the value of English as part of the internationally cooperative inclination and the college's function as an educator in foreign languages. The website is used mainly for administrative announcements, news, and introductions about the college, rather than for communication. College announcements are still made primarily via notice boards scattered around the campus. Intended viewers of the website are simply visitors who are attracted by the two missions of the college given in the introduction page: (1) training foreign language teachers and specialists for Highland and Central Vietnam; and (2) conducting research and providing services related to languages and cultures.

Also on the website, viewers receive an overview of the college's management organisation, training programs, scope and capacity, and infrastructure in a brand new campus with 60 classrooms, lecture halls, and administration section. In addition, the campus has a library with 10,000 titles serving its staff and students in their study and research. Finally, presented on the website is the college's goal of endeavouring to become a leading research centre for foreign language teacher trainers and specialists of high quality for the socio-economic development of Highland and Central Vietnam.

The constraints of technology-supported communications are also reflected in the fact that staff members use different email systems based on their preferences. Looking through the email addresses of the college staff even from the top levels, there are a number of Yahoo, Hotmail, Gmail, and several other free email service providers. Of course, this will not matter if formality and consistency are not taken into account. The explanation for this inconsistency could be that the issue has yet to become a priority for the college and that the principal means of communication has yet to be technology-mediated.

In terms of teaching and learning, communications between teachers and students, and among students themselves, are principally face to face in the classroom. The use of elearning software platforms like WebCT and Blackboard is just a somewhat distant prospect. Even though a project to use Moodle, an open-source course management system, was mentioned in meetings some years ago, this has so far remained an idea on paper.

Nevertheless, there are a few teachers who are keen on the application of computer technology to teaching and learning, asking their students to send written work to them via email so that they can give feedback and correct them before going to class. In addition, the use of office applications like PowerPoint for presentations in class is always encouraged by these teachers. There are also some who make use of the computer lab, which was set up in 2005, for their students to practise word processing and surfing the Internet to look for learning materials. It is noted that during the current study this was the only lab (Figure 1), consisting of 36 computers, available for about 4,000 foreign language majors at the college.

Finally, experience with computers among students is also varied. According to a survey as part of the current study, only $35 \%$ of the students had their own computers at home. The remaining $65 \%$ had to go to the Internet shops outside the campus to use a computer and get access to the Internet, which in 2010 cost about half of their lunch money for one hour of use. On the other hand, quite a few other students $(30 \%$ of 
'fairly good' and 'very good' combined, according to the survey) were very fluent with computer use. It is reported that these students very often used computers for chatting, and sending and receiving emails with friends; some others even wrote blogs and wikis; still others had their diaries on Twitter or, more popularly, Facebook. However, the use of these Internet facilities was just for personal pleasure and entertainment. Bringing them to class for educational purposes was still somewhere in its prenatal stage.

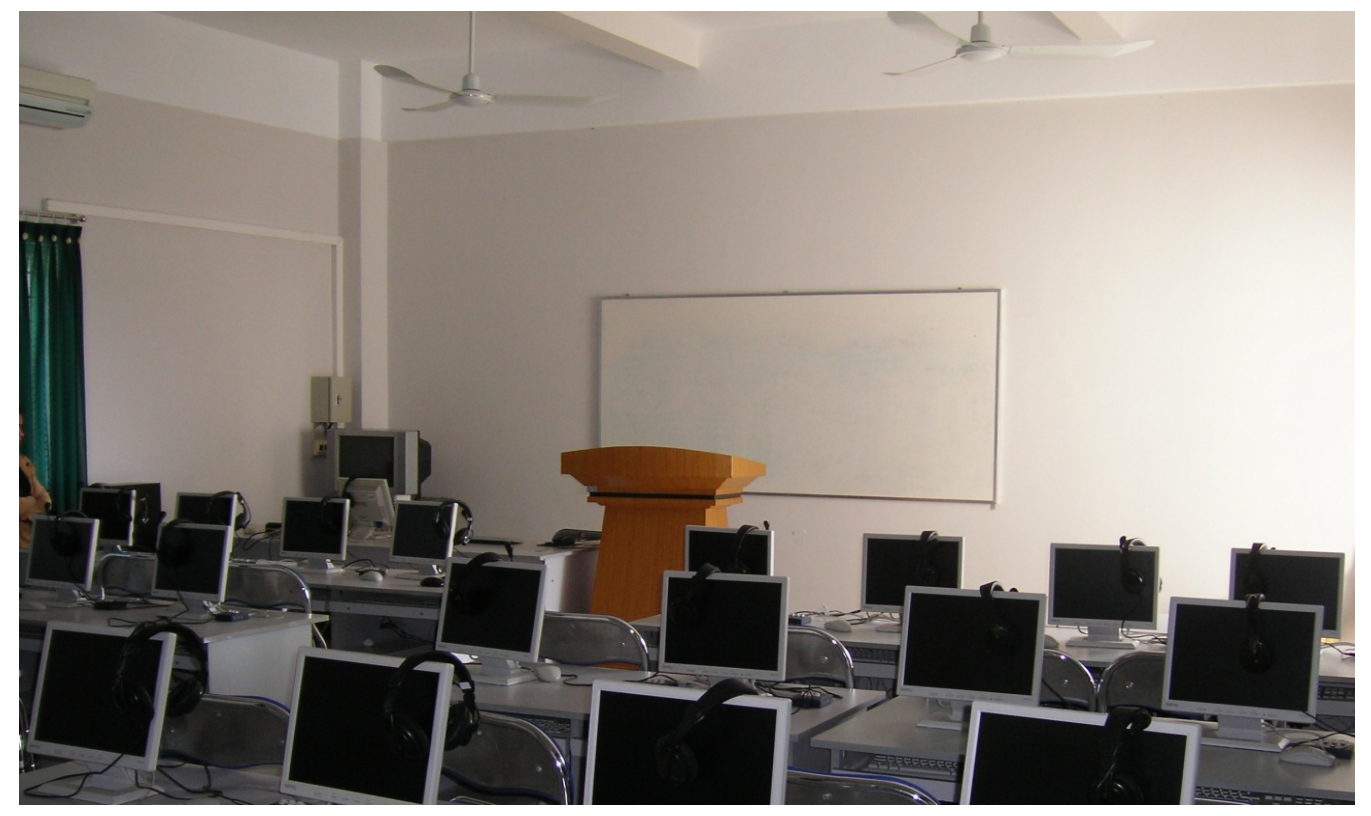

Figure 1: The computer lab at CFL

\section{Purposes of the study}

Grounded on the context of the use of ICT in education in general and language learning, in particular in the Vietnamese sociocultural background, this study aims to investigate the potential for introducing computer-mediated communication in language learning, from a learners' point of view. In other words, acknowledging that learners' perceptions play an essential role in the effectiveness of technology in an educational setting, the paper aims to seek answers for the following research questions in the Vietnamese sociocultural EFL (English as a foreign language) context:

1. What were the students' general attitudes toward the technology-enhanced class?

a. What were students' perceptions of synchronous chat?

b. What were students' perceptions of asynchronous wiki?

c. Which mode of CMC did they prefer?

2. How did the students evaluate the application of $\mathrm{CMC}$ into collaborative learning?

3. What were the benefits students perceived from the course? 


\section{Research methodology}

\section{Research design}

The study was mainly qualitative with the support of some findings from statistical analysis. The design and intended objectives of the study were in line with the sociocultural theory, ICT, and second language acquisition. The combination of both quantitative and qualitative data analysis has recently been considered as mixed methods research (Dörnyei, 2007), or mixed research (Johnson, Onwuegbuzie, \& Turner, 2007), defined as an approach to knowledge that endeavours to take into account "multiple viewpoints, perspectives, positions, and standpoints" (Johnson, et al., 2007, p. 113) and was applied to investigate the learners' reflections on and perceptions of both synchronous and asynchronous CMC in the development of EFL learners' collaborative learning. This innovative research paradigm, according to Luppicini (2007), is the preeminent way to accomplish a thorough understanding of CMC as a complex system. It is an amalgamation that incorporates ideas from qualitative and quantitative research. By congregating numeric details from quantitative data and specific information from qualitative data, a more comprehensive understanding of a target phenomenon can be achieved through differently complementary angles; and the two sets of findings, i.e. quantitative and qualitative, can be cross-verified against each other. Johnson et al (2007) have also named it between-methods triangulation. Above all, the complex nature of classroom environments, as in the current study, "lends itself to mixed methods research" (Dörnyei, 2007, p. 186).

\section{Participants}

This classroom-based research was conducted in the College of Foreign Languages (CFL) in Danag University, a large university in Central Vietnam. The participants included a whole class of 30 students (28 female and 2 male) who were enrolled in a four-year TEFL program to become teachers of English in secondary schools. Ethical procedures were followed to ensure that the informed consent of the students was given throughout the study. These young adults (Table 1), ranging from 21 to 24 years of age, were taking the compulsory American Culture course, taught by the researcher himself, in semester six of the eight-semester Bachelor of Arts program.

Information from a background questionnaire survey showed that there were 18 students from the city, while the remaining 12 were from the provincial regions, which are believed to have certain disadvantages in education in general and computer access in particular (see Table 1). The range of accumulated GPA for the past five semesters was 6.70 for the lowest achiever and 8.75 for the highest. An initial concern was that there would be a difference in language proficiency between these two groups. However, the independent-samples t-test for the place of learning English revealed no statistically significant difference $(\mathrm{t}(58)=1.69, \mathrm{p}=.096)$ in the GPA mean of the city students (Mean: 7.50, SD: .57) and the province students (Mean: 7.27, SD: .38). The questionnaire also demonstrated their desire to have more in-class interaction, both with the teacher and classmates. When asked how much in-class interaction they had with the teacher and other classmates at present and how much interaction they really wanted, the tendency ranged from below $40 \%$ to around $60 \%$ with the teacher, and from $25 \%$ to as high as $70 \%$ with classmates, three times more. This desire for increased contact reflected the class situation where lecturing was the 
principal method of transferring knowledge from the teacher to the learners, which most students felt uncomfortable with.

Table 1: Selected background information about participants

Note: All names are pseudonyms.

\begin{tabular}{|c|c|c|c|c|c|c|c|}
\hline Group & Name & $\begin{array}{l}\text { Graduated } \\
\text { GPA }\end{array}$ & $\begin{array}{l}\text { High } \\
\text { school }\end{array}$ & $\begin{array}{c}\text { PC } \\
\text { skills }\end{array}$ & $\begin{array}{l}\text { Typing } \\
\text { ability }\end{array}$ & $\begin{array}{l}\text { PC use } \\
\text { (months) }\end{array}$ & $\begin{array}{l}\text { PC time use } \\
\text { (hr per week) }\end{array}$ \\
\hline \multirow[t]{3}{*}{01} & T. Huong & 7.58 & province & fairly good & fairly good & $>12$ & 6-10 \\
\hline & Suong & 7.00 & province & very good & fairly good & $>12$ & $>21$ \\
\hline & Hang & 7.64 & city & poor & poor & $>12$ & $6-10$ \\
\hline \multirow[t]{3}{*}{02} & Tuan & 7.28 & province & good & poor & $6-12$ & $6-10$ \\
\hline & H. Phuong & 6.96 & city & fairly good & fairly good & $<3$ & $11-15$ \\
\hline & Tam & 7.17 & city & good & poor & $<3$ & $>21$ \\
\hline \multirow[t]{3}{*}{03} & Binh & 7.65 & city & fairly good & good & $>12$ & $>21$ \\
\hline & Ngan & 7.64 & city & fairly good & fairly good & $>12$ & $>21$ \\
\hline & Yen & 7.38 & province & good & poor & $>12$ & $6-10$ \\
\hline \multirow[t]{3}{*}{04} & Loc & 6.98 & city & good & good & $>12$ & $>21$ \\
\hline & Nga & 7.65 & province & poor & poor & $>12$ & $6-10$ \\
\hline & Thi & 7.45 & city & poor & good & $3-6$ & $1-5$ \\
\hline \multirow[t]{3}{*}{05} & Hoa & 7.84 & city & poor & poor & $<3$ & $1-5$ \\
\hline & Viet & 6.93 & city & poor & poor & $<3$ & $6-10$ \\
\hline & Hanh & 7.90 & city & good & good & $>12$ & $6-10$ \\
\hline \multirow[t]{3}{*}{06} & Thoa & 7.09 & province & poor & poor & $<3$ & $11-15$ \\
\hline & Anh & 6.93 & city & fairly good & fairly good & $>12$ & $>21$ \\
\hline & Nguyen & 7.22 & province & fairly good & poor & $>12$ & $>21$ \\
\hline \multirow[t]{3}{*}{07} & Thuy & 6.70 & province & poor & poor & $>12$ & $6-10$ \\
\hline & Dao & 7.51 & city & good & poor & $>12$ & 11-15 \\
\hline & Nghia & 7.88 & city & poor & poor & $3-6$ & $>21$ \\
\hline \multirow[t]{3}{*}{08} & Nhung & 7.16 & province & poor & poor & $<3$ & $6-10$ \\
\hline & Thang & 7.08 & province & good & good & $<3$ & $6-10$ \\
\hline & V. Hang & 7.48 & province & good & poor & $>12$ & $6-10$ \\
\hline \multirow[t]{3}{*}{09} & Huong & 7.53 & province & poor & poor & $>12$ & 11-15 \\
\hline & Dzung & 7.36 & city & poor & poor & $<3$ & $16-20$ \\
\hline & Thao & 7.42 & city & poor & poor & $<3$ & $11-15$ \\
\hline \multirow[t]{3}{*}{10} & Chuyen & 7.43 & city & good & good & $>12$ & $6-10$ \\
\hline & M. Hang & 8.53 & city & fairly good & fairly good & $>12$ & $>21$ \\
\hline & Phuong & 8.75 & city & good & very good & $>12$ & $>21$ \\
\hline
\end{tabular}

In spite of not having studied with technology before, the students indicated their optimistic evaluation of the benefits of networked computers in their learning, with 28 students agreeing (14) or strongly agreeing (14) that the use of computers is beneficial for learning in general. It is noted that half of the participants expressed their doubts about the usefulness of networked computers in improving speaking skill and pair/group work. This can be explained by the fact that they had never done collaborative learning through computers before and that to them pair/group work definitely involved interaction in person.

Also reported from the questionnaire was that only $60 \%$ owned computers at home. Though half of the students had used computers for more than a year, the selfevaluation of computer and typing skills showed a need for further training. The students spent an average of 12 hours per week working with computers. Most of the online time was used for surfing the Internet and word processing (averagely 6-10 hours/week). The amount of time spent on email, chat and blogs or wikis, on the other hand, was rather low, with the mean at less than five hours/week. Also, seven 
students had never chatted online before, and this number for blogs or wikis was 16 . It is therefore suggested that for computer-based research like the current study to be legitimate, the students need to be computer-literate with information technology in general and with specific programs, such as Yahoo! chat and wikis, in particular. In fact, to ensure all students felt comfortable using the computers, practice sessions were conducted periodically before new tools were introduced.

\section{The CMCL course}

The 12-week American Culture course centred around a large theme that covered various topics relating to life and culture of American people and language. It should also be noted that there was no fixed order for the topics. Rather, the sequence in which the topics were covered in each lesson was a process of negotiation between the teacher and the students. The course had a strong emphasis on achieving cultural and language competence through collaborative learning among students. The course contents and requirements, along with other related issues were put on a website (http: / / americancultures.pbworks.com/) created by the teacher/ researcher with the purpose of helping the students getting used to the application of the Internet into learning. The class learnt in a technology-rich classroom, equipped with 36 computers, on every Friday afternoon for two hours.

During the first week of the class, the teacher introduced the course content and the course requirements, by which in order to pass successfully, the students needed to complete two assignments: an on-going assignment $(30 \%)$ and a final test $(70 \%)$. The final test, usually consisting of a series of multiple-choice questions for easy marking due to the large number of students (370 in all), was administrated by the Department of English at the end of the semester. Meanwhile, class teachers monitored the ongoing assignment during class hours. This on-going task required the students to work in groups of three. They could form the group themselves and worked together throughout the semester. The task was a report about at least three similarities and/or differences between American and Vietnamese culture on a topic of their choice. The students completed the background questionnaire by the end of this week.

The class began their group chat discussion in week four to select a broad topic for their group report after having gone through the course contents and practised chatting on Yahoo! Messenger during the past three weeks with the teacher. Prior to the discussion, each group received a guidelines sheet, giving some suggestions about what should be included in the discussion, such as group leader election, task division, and a proposed discussion time of 30 minutes. Though most of the students conducted their chat task in the classroom where they could easily seek technical help from the teacher, some students asked for permission to work from home, others from the library computers, and still others from Internet shops. During the following week, the students collected sources to prepare for their first draft on their own wiki page that could be accessed later by the teacher and other members.

Week six started with the introduction of the peer review process when the teacher presented the step-by-step training procedure. Students practised the peer review elements with the teacher, based on a sample peer review sheet provided. During the next three weeks in their own time, they took turns exchanging comments on their group members' drafts on the wiki pages. Finally, all groups revised their drafts on week eight and were ready to complete the final group written report by the end of week nine (e.g., http://06spa0210.pbworks.com/). The whole class completed an 
evaluation questionnaire in week ten, when half of them were invited for interviews during the last two weeks of the semester.

\section{Research instruments and data analysis}

The evaluation questionnaire used a 4-point Likert scale from 1 (strongly disagree) to 4 (strongly agree). The use of Likert scale questions allows for different possible responses and gives some indication of strength of feeling. The middle point of "neutral" or "don't know" as used in many popular 5-point Likert scale models was purposefully removed, to encourage students to think deeply before deciding to agree/disagree with 24 items in the questionnaire. The questions were categorised into five groups. Besides item 1 asking about a general evaluation regarding learning with computers, items 2-5 related to synchronous chat; and items 6-10 addressed the use of wikis. Items 11-15 evaluated the students' perceptions of online collaborative learning, while items 16-20 concerned the course benefits. The last items, 21-24, were concerned with affective learning. In addition, six open-ended questions were offered at the end of the questionnaire for students who wished to express personal opinions and suggestions. The questionnaire was tested out on a colleague and a student for any ambiguous questions, and to ensure user friendliness of the included items.

Reponses were tallied and analysed with use of SPSS 17. In order to determine whether the students' answers to an item were at a greater than chance level, the mean Likert score on each item was calculated by running a one-sample two-tailed t-test with the hypothesised mean of 2.5 , as a neutral score of the 4-point scale, and the confidence interval of $95 \%$. Topics emerging from the students' responses to the openended questions were also categorised and analysed.

While the questionnaire was useful for collecting factual, quantitative information, e.g. whether students liked or disliked a particular point or task, it was not so effective for collecting more detailed, qualitative information, such as why they liked or disliked those points or tasks, so an individual interview agenda was prepared for volunteers. The design of this interview is semi-structured to invite more profound thoughts (see Appendix). Transcripts of the interviews were put into Word documents and emailed to individual students to seek any corrections, additions, or further comments arising from their schemata, before being imported into NVivo 8 for analysis.

In addition, various observation techniques, including keeping a diary, taking notes, taking photos, and especially keeping an online blog, were used during the research period. Physical backdrops and individual students were observed for any emerging themes or interesting details and behaviours. The purpose of this observation approach was to enable the teacher/researcher to experience the setting as a whole while immersing himself into the classroom environment. This was valuable data for triangulation with the other sources.

\section{Results and discussion}

\section{The technology-enhanced class}

Regarding the first item of the questionnaire, asking the students to give a brief description of the technology-enhanced class, $23(76.7 \%)$ students agreed that they liked learning with computers, not to mention the other seven $(23.3 \%)$ who strongly agreed with this point. In general, no negative attitude relating to the use of networked 
computers in learning was found. In addition, half of the students who attended the interviews described this class as new, strange, modern, motivating, and interesting among many other positive adjectives, as compared with what they felt were boring and insipid traditional, teacher-fronted classes. General evaluations like "it's lucky for me to be in this class. Other classes must be jealous of us $($.." (M. Hang, group 10; all quotes are entered verbatim) were quite common in interview scripts and comments on the researcher's blog.

Specifically, Yen (03), whose self-evaluated computer skills were poor, shared her feelings when comparing this CMC class with previous traditional ones, "Here in this class ... I think it is more effective because many students could participate at the same time, not like in the previous classes where teachers could not ask all students to speak simultaneously". Another provincial student, Nga (04), though being rather weak in working with computers as reported in the background questionnaire, added that as being the first time of learning in this technology-rich class, she could gather many new things; and it was more enjoyable than previous courses. In addition, Ngan, the most participating member in the same group with Yen, profoundly contributed her ideas, including an equalised participation level with other classmates and highlighting the necessity and significance of developing interactive competence through writing: "in this CMC class, I feel that classmates could share their ideas more equal due to its minimising the language barrier ... because many did not feel confident when discussing face to face".

Phuong was among a few students from Danang city who used computers everyday for learning and mainly entertainment. Her self-evaluated computer and typing skills were highly competent. This most active member of group 10, who moved to the United States to further her study at the end of this course, asserted in her email interview with the researcher that the study environment was open, pressure-free, and independent:

It is an open study environment. It encourages students to freely and equally contribute their ideas when they work in a group.... Students don't feel pressure of being observed by their teacher. Moreover, students are more interested in their study because they can use the social network, which used to be considered as a pastime, in their study. It somehow helps to decrease the pressure from common classes.

Additionally, this kind of class requires students to work independently, and they also have to keep themselves updated with group work, which makes them more responsible. (Phuong, 10)

Furthermore, many students also expressed that what they liked most about the class was being free to share ideas, which they found it difficult to do during traditional class time. Others simply replied that they liked it because they could use computers in class, such as M. Hang (10), "what I like most about CMC class is the fact that I have chance to use computer in my study. Comparing with common classes, CMC class gives more chances for all students to give their opinions to group work rather than only a few individuals". In particular, Chuyen (10), among others, candidly answered that she at first did not understand or figure out what she would do in this course with a bundle of computer and Internet bits and pieces, including Yahoo! chat, LCD projector, PBWiki, YouTube, Google, and so on. However, things became brighter and brighter day by day when she was working with and learning from group members. This illustrates Vygotsky's (1981) zone of proximal development (ZPD), expressing the potential of what a learner can achieve with support from the more experienced. 
There were however several cautions and disadvantages about technology use raised by the students. At the first item in the survey, two students expressed their uncertainty about the effectiveness of the CMC application before calling for more control from the teacher, as they noticed that some students made use of the computers to do 'something else' instead of focusing on the required task. More information about these challenges was found in the fourth interview question, asking them to broach anything they did not like about the course. Most of the students interviewed, 12 out of 15 in fact, touched upon technical issues, which matched the researcher's observation that the exchange process was sometimes delayed because of problems from either the Internet or the computers in the classroom. In addition, there were five students who blamed their limited computer knowledge, which inevitably affected the interaction process. The comments below are representative of the complaints:

Sometimes ... for example, you [the teacher] first instructed us to get into wiki, which I found really complicated, difficult to remember. I had to, many times, ask other classmates for help. (Yen, 03)

What I don't like .... is my computer skills. When learning with technology like this, these skills were very important. It was not easy to follow the teacher's instruction. I wish I had learned these skills before taking this course. (Nguyen, 06)

In general, all of the students responded positively $(\mathrm{M}=3.23, \mathrm{SD}=.43, \mathrm{t}(\mathrm{df})=9.34$, $\mathrm{p}<.01)$ to the first evaluation item, asking if they liked learning in the technologyenhanced environment. This indicates that while there were some technical obstacles that needed to be considered, the advantages that technology brought about outweighed those shortcomings.

\section{Synchronous chat}

Table 2 presents the students' responses to items related to their perceptions of the synchronous chat. The most outstanding aspect observed from the figures was the number of $13(43 \%)$ students who strongly agreed (along with another 14 agreeing) with item 4 that they felt more confident in sharing their ideas in the chat groups. Overall, 27, out of 30, students perceived that the synchronous CMC (SCMC) environment created more self-assurance among the participants. Explanations for this confidence were that many students in the interviews portrayed the chat discussion as creating a more pleasant and convenient environment than the face to face exchanges, thereby motivating them to participate more. As for Tam (02), a student from a provincial region of Nghe An, not being good at either computer or language skills, the absence of facial expressions and other general social, non-verbal cues in the online synchronous exchange motivated and increased her involvement, thereby liberating (Honeycutt, 2001) this more marginal member. Below is what she shared:

Tam: $\quad$... yeah. I could share my ideas in the group in a pleasure way, feeling very comfortably natural, without being shy at all.

Researcher: Don't you feel natural in face to face discussions?

Tam: Uhm, I feel afraid of contributing what I'm not $100 \%$ sure in face to face.

Likewise, Hang (01) explained she could participate more in the chat because she found it difficult to defend her views against opposite opinions raised by other members in face to face modes, even though she tried desperately sometimes. She usually had 'to make concessions' in such discussions. By contrast, she was just able to 
type her opinions at the same time with others on the chat window, thereby creating opportunities for her to share her ideas among the group regardless of her friends "accepting them or not", said Hang. Moreover, Dzung (09) agreed with Thang (08), one of the only two male students in the class, that the chat discussion created more intimacy because it is "the form of learning and playing at the same time" (Thang, 08). In other words, SCMC affords a ludic approach to learning.

Table 2: Students' perceptions of SCMC (N=30)

\begin{tabular}{|l|l|c|c|c|c|}
\hline \multicolumn{2}{|c|}{ Item } & Mean & S.D. & $t$ & $p^{*}$ \\
\hline 2. & I enjoyed the chat discussion with my group members. & 3.03 & .49 & 5.96 & .000 \\
\hline 3. & The chat discussion generated plenty of ideas. & 2.90 & .61 & 3.61 & .001 \\
4. & I felt more confident in sharing my ideas in the chat group. & 3.33 & .66 & 6.91 & .000 \\
5. & Members' contributions during the chat discussion are equal. & 2.90 & .66 & 3.31 & .002 \\
\hline
\end{tabular}

* Significant at $p<.01$

There was a possible relationship between item 5 and item 3 in Table 2. An equal number of students $(23,77 \%)$ agreed and strongly agreed that the chat discussion equalised members' contributions and thus generated plenty of ideas during the discussion. Reiterating Ngan's (03) reply that she could 'talk' much more in the chat, Yen (03) explained that "... everyone had opportunities to talk; everyone shared equal amount of talk; everyone feels that they must talk". What is more, there were at least three students who claimed their most preferred attribute in the chat was that they could roll back and review what was just discussed, thereby helping increase their monitoring of language usage (Sykes, 2005) and "make language manipulable" (O'Rourke, 2008, p. 232). Other students commented on the feature of place independence of the SCMC (Luppicini, 2007). Phuong (10), being sick on the day of her group's discussion, had to stay home and discussed the task with friends from a distance. Her comment highlights the students' perceptions of SCMC, "what I like most in chat discussion section is that I can still contact with my partners without being with them. It also saves time spending on travelling to the meeting place. All I have to do is to be online on time to chat with my partners".

Nevertheless, there were up to eight students who did not agree that the contribution among members was equal. Four of them explained in the interviews that it was because some members did not study the learning material beforehand, so they did not have much to share. Some others had very limited typing skills, which delayed the discussion flow and was therefore interrupted by other members who typed faster. An interesting finding was that those students who were proficient in both computer and language skills disagreed with the equality in group contribution because of the restricted involvement from less proficient students. The latter, on the other hand, supported item 5 above, claiming that the contribution was roughly equal. For example, contrary to Yen's comment above "...everyone shared equal amount of talk", expressing that the participation was roughly equal among the three members, Ngan (03), from the same group, complained in the interview:

Researcher: Can you clarify this point that you did not agree with the equal contribution?

Ngan: $\quad$ As you required that everyone should argue for the selection of the essay topic, I felt that only me and Binh discussed, not Yen.

Researcher: Why do you think this happened? 
Ngan: $\quad$ Uhm, maybe she was easy-going, just let it go; or maybe she was not confident enough to share hers.

A review of this group's discussion transcript shows that Yen was second after Ngan in terms of the level of participation, while Binh was the least contributing member. An explanation for this might be due to individual expectations: the more active members expected more participation from the less contributing members, who in turn felt that their contribution was satisfactory enough. However, perhaps what is more important than quantity is the quality of participation. What Binh contributed was more viable than the other two. A more detailed analysis on the content of the talk is needed to justify this evaluation.

Finally, as far as the quality of the conversation was concerned, a few students mentioned SCMC as a barrier to idea generation. These students complained that their ideas were usually cut into pieces by interrupting turns. Sometimes these ideas could never be completed as the discussion had been distracted to another route. Sometimes ideas typed in the composing window had to be replaced with a new one in order to follow the discussion flow. V. Hang (08) shared her concern:

$$
\begin{array}{ll}
\text { V. Hang: } & \begin{array}{l}
\text { Sometimes I had a certain idea. I was typing ... not finished yet. I hadn't } \\
\text { completed my idea. The other member typed in a message, then adding } \\
\text { more turns. I couldn't keep my idea on. It means the discussion being } \\
\text { diverted to another direction, while my original idea was suspended. }
\end{array} \\
\text { Researcher: } & \text { How about face to face? } \\
\text { V. Hang: } & \begin{array}{l}
\text { I think I would shout to drown others' voices to continue my ideas in a } \\
\text { face to face meeting. }
\end{array} \\
& \ldots
\end{array}
$$

In general, the students had positive perceptions of the use of chat as a means of discussion. Most felt that the participation level was approximately equal across the groups. One of the reasons for this was that whereas other members must spend most of the time listening while one was talking in face to face discussion, three members in the SCMC discussion could express their ideas at the same time. Another reason was the lack of facial expressions motivated and increased participation from those students with lesser language proficiency, who often felt shy and reluctant to share ideas in face to face exchanges. This therefore promoted a higher level of interaction among group members, which in turn increased motivation for learning and negotiation of meaning (Yamada \& Akahori, 2007).

In addition, the technical features, such as scrolling back and place/time independence, of the online synchronous discussion also drew the students' attention with encouraging reflections. SCMC has potential to be a major mediator in social systems of constructing knowledge and sharing experiences through interaction.

\section{Asynchronous wiki}

All students concurred with the questionnaire item 9 (Table 3), asking them if they learned much from their classmates' comments, reflecting the fact that the wiki did assist in the collaborative learning through the process of peer review. This high level 
of response as regards the general evaluation of other members' contribution was not so surprising regarding the Vietnamese style of collaboration, in which harmony and unity are the priorities. As far as the learning benefits were concerned, 28 students expressed their enjoyment of the wiki peer exchanges (item 6) and the effectiveness of this online environment (item 8). Most of these learning benefits resulted from the technological advantages that the wiki platform brought about when up to 26 (87\%) students assented to the assessment of the wiki environment as not so challenging (item 7). Additionally, the learning benefits were evidently perceived since $22(73 \%)$ students agreed that the wiki helped them write more than in traditional classes (item $10)$.

Table 3: Students' perceptions of wiki $(n=30)$

\begin{tabular}{|c|l|c|c|c|c|}
\hline \multicolumn{1}{|c|}{ Item } & Mean & S.D. & $t$ & $p^{*}$ \\
\hline 6. & I enjoyed the wiki peer exchanges. & 3.33 & .61 & 7.53 & .000 \\
\hline 7. & It is easy to work on the wiki. & 3.17 & .65 & 5.64 & .000 \\
\hline 8. & The wiki peer comments helped me revise my draft. & 3.23 & .57 & 7.07 & .000 \\
\hline 9. & I learned much from my classmates' comments. & 3.20 & .41 & 9.42 & .000 \\
\hline 10. & Wiki helped me write more than traditional class. & 2.93 & .70 & 3.43 & .002 \\
\hline
\end{tabular}

* Significant at $p<.01$

These perceptions were positively triangulated with information from the interviews, in which many students expressed their satisfaction by pointing out the user friendly functionalities of PBWiki, such as the ease of editing and commenting, the archive and history review facilities, and the capabilities of multiple review procedure. These technically easy to use functions in turn had helped generate a large number of comments. Tam (02) expressed a view shared by several other students when being asked what she liked most about the wiki below:

Tam: On wiki ... we could exchange and help each other through comments.

Researcher: But, you can still comment on paper. What do you think of the differences?

Tam: Working on the wiki was more motivating. We could have many more comments on wiki. I gave comments to others', then the others gave feedback on mine; then I commented again ... continuously. It was hard to do this on paper.

Similar to Tam, Yen (03) highlighted the convenience of using the wiki for peer feedback, that it was more convenient working on the wiki. She only needed to click on the edit button. In addition, she could see more comments from friends. For her, it was a waste of time doing something like these on paper. On top of the learning and technological benefits, like many other students, Phuong (10) added some affective outcomes that could be gained from the online peer feedback process. She explained that she could sometimes delete a comment that she felt to be incorrect or that might hurt others' emotions; and replace it with a more suitable one:

In wiki peer exchange section, I like being able to share ideas with my partners every time I want and feel free to give them my comments without worrying that I am hurting their feelings. It is because I can think carefully and choose appropriate words before I type them down. More than that, I can delete previous comments and replace them with more suitable ones. (Phuong, 10)

In addition, for Thang (08), the most useful part of the wiki was simply that the writing was read, commented on and corrected by more people, as opposed to his previous 
writings being corrected only by the teacher. Writing on the wiki was different, which he felt was just as if "I've published something". In other words, he wrote not only for the sake of learning; he wrote to communicate. Also from this point of writing with the sense of audience, Tam (02) felt that she must be more responsible for her writing, trying to make it as "smooth as I could since other people would be reading it. It is different when I write for myself".

However, looking from the other side of the issue, some indications of problems were found when two students expressed their indifference to the wiki application, chiefly because of technical issues. Anh (06), for example, felt that "it was fatiguing and inconvenient to edit on the wiki because I had to go to the Internet shop each time. It was more difficult to correct [the drafts] online than on paper because it was harder to read. It was clearer on paper. I could use a pen to read line by line, which I felt really difficult to follow on the computer screen with very small font." Responding to these constructive and critical opinions, the researcher highlighted several reported advantages, including the fact that she could only comment one time on paper, i.e. she had to physically return a draft back to its author, while she could do this as many times as she wanted on the wiki. Moreover, she could delete old comments and replace with those that were more appropriate. Anh responded, "these are some good points. But, these benefits cannot still overshadow the disadvantages" that she encountered. Furthermore, Anh was among eight students who disagreed with questionnaire item 10 asking if the wiki helped them write more than the traditional paper format. It is noted that Anh was from the agricultural province of Quang Binh. She had no access to computers nor the Internet in the flat she rented.

In general, the perceived reflections on the use of the wiki were the benefits concerning the construction of a community of practice (Wheeler, Yeomans \& Wheeler, 2008) including collaboration, learning, and even emotional effects, mainly thanks to the technological advantages this online environment brought about. These benefits, similar to those of the SCMC, appear to outweigh few problems, which could possibly be solved with more comprehensive training in technology use.

\section{Synchronous versus asynchronous}

Of interest were responses to one of the interview questions, encouraging the students to decide which modes of CMC they preferred, based on the affordances provided by each. To those who favoured the use of SCMC (6 out of 15 interviewees), the synchronous discussion provided them with a friendly, non-institutional and pressurefree atmosphere. This mode of online synchronous exchanges was also considered as an interesting and motivating lifebuoy emerging from the condensed curriculum. On the other hand, for other students who preferred the asynchronous CMC (ACMC) mode, the wiki offered a wider variety of affordances than the SCMC. From careful explanation to critical justification, two of the five students who favoured the wiki environment, expressed their partiality toward this type of ACMC collaborative learning style:

... the chat was in fact not completely perfect; it did have some shortcomings as compared to face to face discussions. I haven't however found any shortcomings from the wiki. (M. Hang, 10)

Generally, I don't hate either of them; but if I have to choose, I would say I prefer the wiki exchange because it has more functions than the chat... In addition, the wiki 
itself also included the chat discussion. We could give comments in a more convenient way. Moreover, we could view and review the work as many times as we wanted to, different from the chat discussion which could not save scripts online. Everything on the chat disappeared when we logged out ... (Hanh, 05)

As far as sociotechnical affordances (Lund, 2008) are concerned, the archive function of Yahoo! Messenger, like many other chat tools available could only save chat scripts locally, i.e. on the computer. The students could not refer back to the scripts on another computer. Hanh (05), like many other students in this class, was in this situation. As she had used a classroom computer to discuss within her group previously, she could not review the discussion history by using computers in the library or, more often, in Internet shops. Conversely, the wiki saved all entries online and they could be accessed anywhere, and of course, anytime.

If one of the crucial questions raised by White (2003) is "how to arouse and maintain in learners a desire to interact" (p. 55), then the online learning context in the current study somewhat solved the problem by helping the students to perceive the significance of the CMC-based learning environment and facilitating their willingness to interact meaningfully within the affordances this environment provided. In other words, it is the affordances of the asynchronous mode of CMC that helped involve more sustained commitment to the collaborative work among group members than the SCMC, as suggested by Phuong (10), "I prefer wiki exchange because it does help us improve our skills more than chat discussion. Moreover, we work harder in wiki exchange than in chat discussion. Chat discussion is just a small part while wiki exchange is with us for almost the whole course".

Finally, four students reported that they could not decide which one they preferred. Rather, they liked both, elucidating that each mode of CMC had its particular features and characteristics, complementing each other. For Nga (04), 'each had its own merits'.

\section{Collaborative opportunities}

The descriptive statistics in Table 4 show that all 30 students indicated in item 11 their agreement or strong agreement with the collaborative learning opportunities the course offered. Likewise, most of them (28 out of 30) affirmed that they gained new ways of learning from the collaborative process (item 13), which partly resulted from the larger number of comments they entered on the ten wiki sites. Additionally, the time involvement in the SCMC discussion and especially the large number of comments in the wiki peer review process, along with the researcher/teacher's sustained observation confirmed the high number of students (item 15) responding positively regarding the amount of interaction via computers throughout the course.

Table 4: Students' perceptions of collaborative learning $(\mathrm{N}=30)$

\begin{tabular}{|c|c|c|c|c|}
\hline Item & Mean & S.D. & $t$ & $p^{*}$ \\
\hline 11. I enjoyed the collaborative learning opportunities. & 3.20 & .41 & 9.42 & .000 \\
\hline 12. I am satisfied with the final collaborative product. & 2.83 & .65 & 2.82 & .009 \\
\hline 13. I gained new ways of learning from the collaborative work. & 3.10 & .48 & 6.84 & .000 \\
\hline 14. Everyone in the group contributed equally to the final work. & 2.83 & .70 & 2.61 & .014 \\
\hline 15. I had a lot of interaction with my classmates via the computers. & 2.93 & .69 & 3.43 & .002 \\
\hline
\end{tabular}

* Significant at $p<.01$ 
However, as indicated in item 14, not many students were satisfied with the level of equal contribution to the final report. Answers to this item also correlate to responses to item 12, evaluating the final collaborative report, in which six students denied that they were satisfied and one student, Nghia (07), strongly disagreed. Nghia was from a provincial region with a self-evaluation of limited computer skills but high language proficiency evident in the accumulated GPA of 7.88 (ranking 4th in the class). As a group leader, she was the most participating member in both the chat discussion and the wiki peer review processes. In terms of the latter process, she logged in 76 times, compared to 37 and 6 times for the other members. Nghia produced $73 \%$ (74 out of 102) of the group comments. On being asked why she was not satisfied with the final group work, she explained that at the time the evaluation questionnaire was delivered her group work had not finished due to the limited engagement of the other two members and she was very worried about the result. It can be inferred that Nghia, like Ngan (03) as discussed above, felt highly responsible and expected much from other members and of the quality of the final collaborative report, which made her feel upset regarding the group result. Another important conclusion drawn from what Nghia said is that CMC fosters process-driven learning: collaboration on the wiki could be prolonged over a sustained period of time.

Of interest was part of the second interview question asking what the students liked most about their final collaborative product. This should have been changed to 'do you like your final group report? Why/not?' because 11 out of 15 interviewees expressed a lack of satisfaction with the final report. Part of the explanation for this response may be the Vietnamese style of self-assessment, especially in face to face encounters like an interview. In other words, the Vietnamese can feel uneasy or shy when they say something good about themselves. They therefore tend to reduce the level of selfassessment, from good to average, from average to bad, for example. Another reason lies in the students' expectations of computers. There may have been a belief in the 'fire' metaphor, i.e. the closer to the fire one is, the warmer one automatically feels. The students might have an analogical thought that just because they learned with computers, their results must certainly be better.

Other explanations can be found from the interview data, including disagreements among group members and dissatisfaction with the report itself, such as paragraph organisation and grammatical errors. These issues were however similar in the traditional method of collaborative learning and had no relation to the technological application. In fact, when asked how it would have compared with the same task done by the previous methods, most of them responded that the new style of learning with CMC was much better although some issues occurred as above. Ngan (03), for example, in spite of assessing her group report at an average level, compared:

... I felt that the other members were more willing to listen to me when correcting on this. It seemed difficult for me to persuade them in the direct way like face-to-face. I just made use of the comment functions on the wiki to add mine. They looked more diagrammatic and logical.

Similarly, all three members of group 10 were satisfied with their final report as a collaborative product, as summarised by Phuong, "what I like most in the final collaborative product is that everyone contributed their own work to make a complete final product. Also, we spent time together to revise and improve our writing." 
To sum up, the students responded highly positively to the technology-supported collaborative learning process leading to completion of the final reports. Although the satisfaction level with the end product was not so high, as reflected during the interviews, the perceptions of the usefulness of $\mathrm{CMC}$ in collaborative practices were constructive and optimistic, compared with the traditional methods of collaboration.

\section{The course benefits}

The students' reflections on and perceptions of the various benefits from the CMCintegrated course are of two types, according to the questionnaire items: those relating to specific skills and areas and those concerning future impacts (Table 5). First, it is no surprise to learn from item 16 that most of the students (28 out of 30) agreed with the idea that this course helped them improve their computer skills. For most of these Vietnamese learners, the first time to experience the use of CMC, both synchronous and asynchronous, in an academic setting did transform their view of the application of computers in language learning. This experience also helped upgrade their computer aptitude from feeling anxiously unfamiliar to a confident level, for example, "now I feel acquainted to it and I think I will be able to learn better with this method" (Tam, 02). Only two students (Phuong and M. Hang, 10) did not concur with item 16. They explained that the computer applications used in the course were so familiar to them since they used them every day. Hence, they found no improvement via this course, as compared to their existing knowledge of computers.

Table 5: Students' perceptions of the course benefits $(n=30)$

\begin{tabular}{|c|l|c|c|c|c|}
\hline \multicolumn{1}{|c|}{ Item } & Mean & S.D. & $t$ & $p^{*}$ \\
\hline 16. & This course helped improve my computer skills. & 3.40 & .62 & 7.93 & .000 \\
\hline 17. & My English improves as a result of CMC collaboration. & 2.93 & .45 & 5.28 & .000 \\
\hline 18. & My grammar improves as a result of CMC collaboration. & 2.77 & .50 & 2.90 & .007 \\
\hline 19. & My writing improves as a result of CMC collaboration. & 2.97 & .41 & 6.18 & .000 \\
\hline 20. & My vocabulary improves as a result of CMC collaboration. & 2.97 & .49 & 5.22 & .000 \\
\hline 21. & I felt more involved in learning during this course. & 3.00 & .53 & 5.21 & .000 \\
\hline 22. & I enjoy learning English more after this class. & 3.17 & .46 & 7.92 & .000 \\
\hline 23. & I enjoy collaborative learning more after this class. & 3.03 & .49 & 5.96 & .000 \\
\hline 24. & I will recommend this way of learning to my friends. & 3.43 & .50 & 10.14 & .000 \\
\hline
\end{tabular}

* Significant at $p<.01$

Due perhaps to the 'fire' metaphor discussed above, perceived impressions of the improvement in English were however not so high, with the mean of 2.93 (item 17), slightly above the hypothesised mean of 2.50 . Various responses mentioned in the questionnaire as well as in the interviews showed that writing skills along with vocabulary and sentence structures was essentially developed through the course while other skills and areas, such as reading, grammar, and speaking were occasionally referred to. It is not difficult to find explanations for these perceptions since the whole collaborative process focused mostly on writing along with the final product as a written report. An exception might be about the chat discussion, in which the language used was half written and half spoken, as realised by many interviewees. This shows that the learners in this course could discriminate linguistic differences between the two modes of exchanges, i.e. SCMC and ACMC. 
Remarkably, some students mentioned a few metalinguistic aspects that were considered useful for future language development, like "... it improves my ability to think more quickly in English, and respond more quickly to requests or questions ..." (Ngan, 03). Similarly, Phuong (10) expressed her view in the email interview that it did in some ways, such as helping towards using English more appropriately or giving more chances for everyone to contribute their opinions, which was hardly seen in common classes. It is of course admitted that a short course of only 12 weeks applying, not to mention introducing, technology into an academic environment cannot be expected to result in an obvious improvement in the learners' language proficiency. M. Hang (10) helped to conclude this part, regarding the perceived benefits of the CMCintegrated course on language development:

Uhm, I think that if this way of learning was applied much longer, much would be improved. We in fact used just a little bit of CMC to write a short essay, it was hard to say my English was improved after this course. (M. Hang, 10)

Regarding the future impacts of the CMC-integrated course, responses to the last four questionnaire items were greatly encouraging. The majority of students agreed with item 21 that they felt more engaged in learning during and after the course. This affective realisation is essentially significant in collaborative learning (McLoughlin, 2002), according to the communicative language teaching (CLT) approach to language learning and Vygotsky's sociocultural theory that requires an individual to be actively involved in activities within a social setting, through which knowledge will be acquired naturally from other individuals. Similarly, they also enjoyed learning English (item 22) and collaboration (item 23) more after this class, with the mean of 3.17 and 3.03 respectively, considerably higher than the hypothesised mean of 2.50 . Key factors for these positive attitudes include the new and motivating application of $\mathrm{CMC}$ with the two modes and the encouraging collaborative task that involved more interaction among learners.

Notably, as shown in item 24, all students expressed their willingness to recommend this learning style to the next generations of language students. In addition, when being asked what advice they would give to future students who may attend a similar CMC-enhanced course, it is not surprising to learn that most students (22 out of 30) prioritised some preparation regarding computer knowledge and typing skills to be capable of learning more effectively. This again emphasises the importance of technical instruction as a key factor for a successful CMC-integrated course as far as these particular Vietnamese students are concerned. Furthermore, several pieces of advice were orientated to the language and task preparation to minimise disagreements and to ensure the successfulness of group work. Other advice was interestingly focused on the roles of the teacher as a course facilitator, a group work regulator, and also a technical problem coordinator, adding that students "should pay attention to what the teacher instructs them" (Chuyen, 10) and that "don't be shy to talk to your teacher about your problems" (Nghia, 07). Lastly, some called for more cooperation within group members because "team work is very important. Each member of the group has to know how to get others involved so that the final result is satisfactory" (Nghia, 07).

Finally, last minute remarks on the last, open ended item in the questionnaire left quite a few critical and thoughtful comments, along with certainly a large number of general appreciative comments. Ngan (03), for example, favourably confirmed that this way of learning brought her a lot of interest and that her group members had chances to express more ideas that they might not be able to do in direct speech. Similarly, M. 
Hang (10) auspiciously expressed her preference for this way of learning as being very interesting and that learning is not limited to the classroom anymore. On the other hand, in line with within-class suggestions from some students, such as requiring more control from the teacher and more skills included into the project, Nga (04) and Binh (03) called for more investment from the college administrative level for the improvement of the computer and network systems on campus before any application of CMCL into a language class. Anh (06), in spite of holding negative impressions about CMC throughout the collaborative process, modified her evaluation by the end of the course, suggesting a combination with the traditional method: "the application of CMCL is still interesting and useful. As for me, it's very good to combine this way with traditional modes" (Anh, 06).

\section{Conclusions}

On looking at the data overall, technological expertise turned out to be the biggest perceived barrier toward the success of a technology-enhanced course. For these Vietnamese students whose computer knowledge was limited, well-designed and comprehensive training programs are recommended before any application of CMC into a language class. Other, less prominent, issues, according to the students, were those relating to language and task preparation and those concerning the college's infrastructure. Other than those, positive attitudes toward to the use of CMC in collaboration were evidently experienced both from answers to the evaluation questionnaire and in the interviews. All the participants expressed their preference for learning with the support of computers and indicated that they wished for and were willing to have more CMC-enhanced courses like the current one in future.

Moreover, an equal number of students preferred either chat or wiki while quite a few liked both as they could not decide which one they favoured. They also perceived that each mode of CMC supported their learning and collaboration in different ways, complementing each other. While the chat discussion increased and equalised group members' participation and contribution, the wiki peer review supported them by creating an environment in which they not only learnt English but also exchanged social and emotional matters. Both of these generated more confidence and motivation toward the collaborative learning process among the students. The participants reflecting on their experience noted that their computer abilities improved considerably, although the perceived improvements in language skills were not significant due to the short time of using CMC in the language class. Furthermore, as a result of these motivational aspects of $\mathrm{CMCL}$, the students felt they were more involved in learning and especially learning English with collaboration during and after the CMCL course. All of them were willing to recommend this learning type to the next generations of students.

Obviously, the CMC technologies create an affective ecology for the students. Flow theory, as discussed by Egbert (2005) in relation to foreign language learning, provides a useful lens for reflection in the current study, bringing mixed attitudes toward affordances provided by the CMCL environment. Egbert highlighted the importance of the relationship between skills and challenges to the flow experience. For those students who were 'in the flow', i.e. their existing language and computer skills and challenges generated by the new learning environment were balanced, learning in this technology-enhanced setting can be considered a lifebuoy, providing a relaxation from the concentrated schedule of so many in-class hours. This is evident in one of the 
comments, "I like the chat discussion last week because it helps me relax after a weeklong hard work" (Tuan, 02). For this student, the chat discussion is not counted as part of his learning load. It is instead an entertaining and relaxing mediator. This may be because many of these students' previous experience of computers was more social than academic. Introducing $\mathrm{CMC}$ into the classroom therefore means bringing playing into learning. Popular evaluations from 'in the flow' students towards the CMC environments included freedom to share ideas, more pleasure, and low pressure. The fact that CMC affords a ludic approach to learning creates much motivation and therefore involvement.

Additionally, when it comes to comparison, the wiki-based asynchronous peer exchanges prove to be more user-friendly than the Yahoo! synchronous discussion. This made the students more committed to and prepared to invest more effort in the collaborative process as well as the final product. Below is what Phuong (10) personally shared on the researcher's blog. Phuong expressed her thanks to the researcher for providing her and her classmates with a new way of learning. For her, the wiki was certainly not only a cognitive environment for learning and collaboration but also the social platform for sharing emotions.

Wiki does encourage us to leave comments on our partners' writings. Just visit group

10 to see that 1 . Furthermore, this is also a good place for us to share things

happening in our daily lives, which are now gradually reduced to meet the study

requirements. I myself feel so close to my crew thanks to wiki. Thanks so much for this

helpful website, teacher. (Phuong, 10)

Conversely, the integration of $\mathrm{CMC}$ into conventional classroom practices may also bring added burdens into learning for most other students, who were not 'in the flow', i.e. their existing language and computer skills did not catch up with the challenges. Responses to the challenges were mixed. Some students raised the issues of technology-related knowledge as the major barrier for them to overcome and took a setback stance. In contrast, the majority of 'not in the flow' participants took a more adaptive attitude toward the CMC-based learning model. They took opportunities to request technological as well as cognitive support from the teacher and other class members, by which they created and put themselves in the ZPD, as indicated previously.

The students experienced the online environment as one to which they could and should contribute, as expressed by Yen (03) that "... everyone feels that they must talk." It is this distribution of expertise that corroborates the fact that the students themselves are considered as a significant source of knowledge. More than just mediation for interaction, $\mathrm{CMC}$ has turned communication into substance (Dillenbourg, 2005), transforming the learners from pure information receivers to active knowledge contributors.

\section{Implications}

The research supports the view that the integration of CMC technologies into collaborative learning, from the learners' perspective, is feasible and applicable. However, in order to transform this potential into practical application, much preparation is needed. The current study reveals that learners' technology-related expertise is a crucial element, deciding the success (or failure) of the CMC application into learning. Levels of computer familiarity as well as typing skills should be carefully 
gauged before an actual classroom practice is introduced. Based on this type of survey, the teacher may decide how much and in which area of technology knowledge learners need to be trained and equipped. Most importantly, the survey should also include an examination of learners' subject-related proficiency levels, derived from which the teacher designs suitable tasks and assignments that should be within the learners' ZPD. Complementary to this, the purpose of collaborative learning and CMC integration should be clearly explained to learners. Several classroom hours should be spent on discussing with students benefits and challenges that collaborative learning in general and CMCL in particular may bring about. Part of the survey should also include an option, in which students may choose not to participate in a technologyenhanced classroom. Clearly, learning with technology should not be made compulsory at an introductory stage. As informed by the current study, CMCL does not automatically bring about better learning than the traditional method of collaborative learning. Learners' motivation and willingness to participate appear to be a key to success.

Furthermore, ICT infrastructure is another crucial issue. An examination of the technology capacity of the institution is needed, including the capabilities of the computers installed in labs, how fast and consistent the network is, and what types of software are required for student use, among many other aspects, based on which the teacher may need to adjust his/her plan of action. It is important to stress that education is a system; when a new element, CMC in this case, enters the system, it triggers some turbulence and disorganises the system (Menezes, 2008). The rising issue of how an application of CMC in the classroom fits with the current curriculum, as a system, needs to be investigated.

Finally, another pedagogical significance of the current study is that the participants were teacher trainees. Pedagogically, people tend to teach in the way that they have been taught. This is one of the ideas that inspired the researcher to select this TEFL class as the subject of study. By introducing some of the current approaches to language teaching and learning, it is hoped that the students will be able to apply what they learned from this course in a technology-enhanced environment, with a range of $\mathrm{CMC}$ tools, in their future teaching careers in secondary schools of various levels.

\section{Acknowledgment}

The author would like to thank Dr Gillian Skyrme for her proofreading and critical comments on the paper.

\section{References}

Abrams, Z. I. (2006). From theory to practice: Intracultural CMC in the L2 classroom. In L. Ducate \& N. Arnold (Eds.), Calling on CALL: From theory and research to new directions in foreign language teaching (pp. 181-210). San Marcos, TX: CALICO.

Block, D. (2003). The social turn in second language acquisition. Edinburgh: Edinburgh University Press.

Chun, D. (2008). Computer-mediated discourse in instructed environments. In S. S. Magnan (Ed.), Mediating discourse online (pp. 15-46). Amsterdam: John Benjamins.

Dillenbourg, P. (2005). Designing biases that augment socio-cognitive interactions. In R. Bromme, W. Hesse \& H. Spada (Eds.), Barriers and biases in computer-mediated knowledge communication - and how they may be overcome (pp. 243-264). Dordrecht, Netherlands: Kluwer. 
Dörnyei, Z. (2007). Research methods in applied linguistics. Oxford: Oxford University Press.

Egbert, J. (2005). Flow as a model for CALL research. In J. Egbert \& G. M. Petrie (Eds.), CALL research perspectives (pp. 129-139). Mahwah, NJ: Lawrence Erlbaum Associates.

Fang, X. \& Warschauer, M. (2004). Technology and curriculum reform in China: A case study. TESOL Quarterly, 38(2), 301-323.

Honeycutt, L. (2001). Comparing e-mail and synchronous conferencing in online peer response. Written Communication, 18(1), 26-60. http://dx.doi.org/10.1177/0741088301018001002

Johnson, R. B., Onwuegbuzie, A. J. \& Turner, L. A. (2007). Toward a definition of mixed methods research. Journal of Mixed Methods Research, 1(2), 112-133. http: / / dx.doi.org/ 10.1177/ 1558689806298224

Kern, R. (2006). Perspectives on technology in learning and teaching languages. TESOL Quarterly, 40(1), 183-210.

Lantolf, J. P. \& Thorne, S. L. (2007). Sociocultural theory and second language learning. In B. VanPatten \& J. Williams (Eds.), Theories in second language acquisition: An introduction (pp. 197221). Mahwah, NJ: Lawrence Erlbaum Associates.

Lee, L. (2010). Exploring wiki-mediated collaborative writing: A case study in an elementary Spanish course. CALICO Journal, 27(2), 260-276. https: / / calico.org/memberBrowse.php?action=article\&id $=792$

Liu, J. \& Sadler, R. W. (2003). The effect and affect of peer review in electronic versus traditional modes on L2 writing. Journal of English for Academic Purposes, 2(3), 193-227. http: / / dx.doi.org/ 10.1016/S1475-1585(03)00025-0

Lund, A. (2008). Wikis: A collective approach to language production. ReCALL, 20(01), 35-54. http: / / dx.doi.org/10.1017/S0958344008000414

Luppicini, R. (2007). Review of computer mediated communication research for education. Instructional Science, 35(2), 141-185. http:/ / dx.doi.org/10.1007/s11251-006-9001-6

McLoughlin, C. (2002). Computer supported teamwork: An integrative approach to evaluating cooperative learning in an online environment. Australian Journal of Educational Technology, 18(2), 227-254. http:/ / www.ascilite.org.au/ajet/ajet18/mcloughlin.html

Menezes, V. (2008). CALL: A strange attractor in language education in South America. Paper presented at the WorldCALL 2008: CALL Bridges the World (Fukuoka, Japan, 5-8 August, 2008). [verified 18 Dec 2011] http: / / www.j-let.org/ wcf/proceedings / a-002.pdf

Nguyen, L. V. (2008). Computer mediated communication and foreign language education: Pedagogical features. International Journal of Instructional Technology and Distance Learning, 5(12), 23-44. http:/ / www.itdl.org/Journal/ Dec_08/article02.htm

Nguyen, L. V. (2010). Computer mediated collaborative learning within a communicative language teaching approach: A sociocultural perspective. The Asian EFL Journal Quarterly, 12(1), 202-233. http: / / www.asian-efl-journal.com/March_2010_lvn.php

Norton, B. (2009). Identity, literacy, and English language teaching across time and space. Paper presented at the IATEFL Conference (Cardiff, UK, 1-4 April, 2009).

O'Dowd, R. (Ed.). (2007). Online intercultural exchange: An introduction for foreign language teachers. Clevedon, UK: Multilingual Matters.

O'Rourke, B. (2008). The other C in CMC: What alternative data sources can tell us about textbased synchronous computer-mediated communication and language learning. Computer Assisted Language Learning, 21(3), 227-251. http:/ / dx.doi.org/10.1080/09588220802090253 
Stahl, G., Koschmann, T. \& Suthers, D. (2006). Computer-supported collaborative learning: An historical perspective. In R. K. Sawyer (Ed.), Cambridge handbook of the learning sciences (pp. 409-426). Cambridge: Cambridge University Press.

Sykes, J. (2005). Synchronous CMC and pragmatic development: Effects of oral and written chat. The CALICO Journal, 22(3), 399-431.

https: / / calico.org/memberBrowse.php?action=article\&id=142

Thorne, S. L. (2008). Computer-mediated communication. In N. Hornberger \& N. V. DuesenScholl (Eds.), Encyclopedia of language and education, Volume 4: Second and foreign language education (2nd ed., pp. 325-336). Kluwer: Springer Verlag.

Vietnamese Government (2008). Government's decree on information technology application in government agencies. (Decree 64/2007/ N_-CP). Hanoi: Vietnamese Government.

Vygotsky, L. S. (1981). The instrumental method in psychology. In J. Wertsch (Ed.), The concept of activity in Soviet psychology (pp. 143-184). NY: M.E. Sharpe.

Warschauer, M. (2010). Digital literacy studies: Progress and propects. In M. Byanham \& M. Prinsloo (Eds.), The future of literacy studies (pp. 123-140). Houndmills, Basingstoke, UK: Palgrave Macmillan.

Wheeler, S., Yeomans, P. \& Wheeler, D. (2008). The good, the bad and the wiki: Evaluating student-generated content for collaborative learning. British Journal of Educational Technology, 39(6), 987-995. http://dx.doi.org/10.1111/j.1467-8535.2007.00799.x

White, C. (2003). Language learning in distance education. Cambridge: Cambridge University Press.

Yamada, M. \& Akahori, K. (2007). Social presence in synchronous CMC-based language learning: How does it affect the productive performance and consciousness of learning objectives? Computer Assisted Language Learning, 20(1), 37-65. http: / / dx.doi.org/10.1080/09588220601118503

\section{Appendix: Interview questions}

1. What do you think of this CMC-enhanced class? How would you describe it?

2. What do you like most about this CMC class? In the chat discussion section? In the wiki peer exchange section? In the final collaborative product?

3. Which one do you prefer: chat discussions or wiki exchange or both? Why?

4. Is there anything you don't like about this course?

5. Do you think CMC helps you improve your English? How?

6. Which language skills do you think you develop most?

7. Which activities of this course were the most helpful for learning English?

8. What are skills gained from this class that you will need in the future?

9. How did you feel about learning English with computers at the beginning of the course (in February) and then at the end of the course (in May)?

10. Can you identify experiences that were critical incidents or turning points for you during the course?

11. Would you like to attend another similar CMC collaborative class in the future?

12. How will the theme "The Year of ICT" affect you as a language student and as a future teacher? 
Author: Dr Long V Nguyen

College of Foreign Languages, University of Danang, Danang City, Vietnam

Email: nvlong@cfl.udn.vn Web: http: / / www.cfl.udn.vn/

Long V Nguyen $P h D$ is lecturer in applied linguistics at the University of Danang. He has published widely in the fields of educational technology and communication in foreign language learning and teaching, collaborative learning, and language teacher education.

Please cite as: Nguyen, L. V. (2011). Learners' reflections on and perceptions of computer-mediated communication in a language classroom: A Vietnamese perspective. In Hong, K. S. \& Lai, K. W. (Eds), ICT for accessible, effective and efficient higher education: Experiences of Southeast Asia. Australasian Journal of Educational Technology, 27(Special issue, 8), 1413-1436.

http:// www.ascilite.org.au/ajet/ajet27/nguyen.html 